\title{
European Organization for Research and Treatment of Cancer
}

National Cancer Institute

\section{Source}

National Cancer Institute. European Organization for Research and Treatment of Cancer.

NCI Thesaurus. Code C19741.

A group with aims to conduct, develop, coordinate, and stimulate laboratory and clinical research in Europe to improve the management of cancer and related problems by increasing survival but also patients' quality of life. There are more than 60 institutions and departments that have been recognized by EORTC as affiliated. These groups conduct, on a voluntary basis, laboratory research and/or clinical trials on all types of cancers using a multidisciplinary approach. EORTC maintains close working relationship with $\mathrm{NCl}$ and the British Cancer Research United King dom in London. 